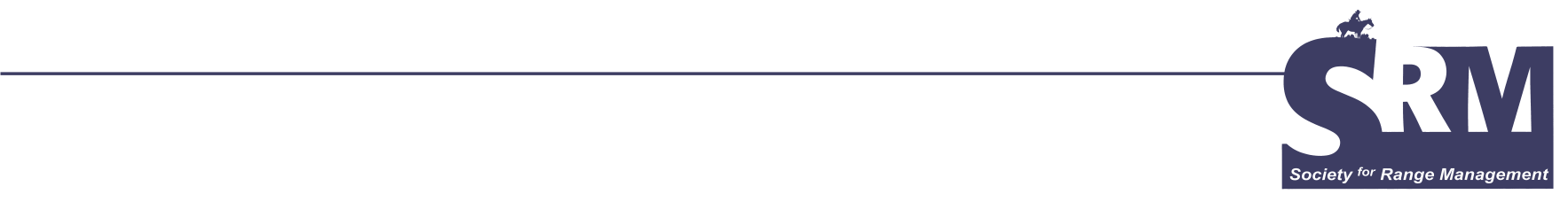

\title{
Selected Essays on Science, Rangelands, and Roles of the Society for Range Management
}

\section{By Kris Havstad}

W e are members of a field profession. As a scientist, I am also a member of a profession based on the written word. Often, unfortunately, in writing about this field, our chosen words often reflect the perpetual nature of the environment: dry, dusty, and typically sparse. Maybe it is part of the nature of objective scientific writing. The following collection contains 4 short essays that have been written over recent years as an alternative to this more xeric verbiage. Mostly, these have been written to be buried on the 3rd page of an obscure SRM section newsletter. A few have appeared in the SRM Member Resource News. It is my impression that these essays have been read by 2 people-me, and another person who thinks I am of questionable intellect and who can't wait to read my latest rambling as further proof of his conviction, and who then shares his reasoning with me.

I have assembled these essays into a single collection here to offer an array of viewpoints for readers of Rangelands. These viewpoints range from perspectives on the sufficiency of our science to cultural statements expressed within a dairy parlor in China. The central thread is probably best summed as a passion for the profession occasionally tempered by a sense of humor for my minor role in that profession.

\section{Cannibalism, Transmissible Spongiform Encephalopathy, and Rangeland Management}

In the 1950s, as thoroughly described in the book "Deadly Feasts" by Richard Rhodes, Dr Carleton Gajdusek (pronounced GUY-du-shek) traveled to New Guinea and began investigating the origins of a degenerative human brain disease called kuru. Gajdusek had graduated from Harvard
Medical School, studied under Linus Pauling at Cal Tech, and had worked on hepatitis, the plague, hemorrhagic fever, encephalitis, and rabies in various locations around the world. Described by Rhodes as an extremely intelligent, manically energetic, fearless, and self-centered scientist, Gajdusek began a very systematic study of this disease common to women and young children within tribal groups of reported cannibals called the Fore in remote parts of New Guinea. The symptoms of this disease mirrored those of other degenerative brain diseases and included tremors, hysteria, dementia, and eventual death. At its peak occurrence kuru was reported to have killed $1 \%$ of the population annually, mostly women and young children in kinship groups, who would have prepared deceased relatives for consumption in mortuary feasts. The agent or agents of kuru were unknown. Gajdusek began a series of studies and systematic autopsies of the Fore killed by kuru. In the late 1950s, a neuropathologist with the National Institutes of Health (NIH), Igor Klatzo, began studies of tissues collected by Gajdusek, which had been sent to labs in Maryland. Very quickly Klatzo associated kuru with brain disease cases reported in Germany by Drs Creutzfeldt and Jacobs (Creutzfeldt-Jacobs Disease, CJD) in the 1910s and 1920s. CJD was known to occur globally and was broadly diagnosed as a spongiform encephalopathy, or a disease in which the brain is characterized by a sponge-like appearance of holes. At a similar time, William (Bill) Hadlow, a veterinary pathologist based in Hamilton, Montana, and working for the NIH on Rocky Mountain spotted fever, was sent to England to study a disease of sheep called scrapie that had begun to occur in US flocks. First reported in the British Isles in 1730, scrapie-infected sheep staggered, developed tremors, and eventually died. In 1930, the disease was shown to be 
infectious, but the specific agent or agents were unknown. In 1959, Hadlow became aware of Gajdusek's work on the Fore tribe and the strikingly similar brain tissue effects of kuru and the effects he had observed in scrapie-infected sheep. Hadlow and Gajdusek met late in 1959 and began a lengthy period of collaborations on these similar diseases that shared unique characteristics, including lengthy incubation periods and dementia, yet that lacked normal signs of infection such as tissue inflammation and fever. Hadlow, after returning to Montana, learned that mink also contracted a scrapie-like disease, and infected tissues transmitted that disease when fed to other mink. By the early 1960s, their activities, the seriousness of these diseases, and their merging similarities attracted other scientists including Mike Alpers, a government physician; Elizabeth Beck, a neuropathologist based in London; and Patricia Merz, a PhD student, self-taught in the skills of electron microscopy (EM). Alpers was involved in experiments that showed that tissue from kuru victims would transmit the disease to primates, Beck confirmed that the disease transmitted to primates was kuru, and Merz's high-quality EM pictures of infected brain tissues showed for the first time a possible actual agent of these transmissible spongiform encephalopathies (TSE) - twisted fibers of what was later identified as proteinaceous infected particles or prions. Though the actual agent is still not known, and may yet turn out to be a virus, tremendous progress involving this problem was made by a highly diverse group working towards a common goal. In 1976, Carleton Gajdusek was awarded the Nobel Prize in medicine for his work on kuru and TSE.

In the mid-1980s, the subject of TSEs took on a more human side. Beef cattle in Great Britain were sickened by a new degenerative brain disease that caused aggressive and nervous behavior that led to death. The media quickly labeled this "mad cow disease" but it was obviously a bovine form of spongiform encephalopathy (BSE). Subsequent research identified that infected cattle had been fed scrapiecontaminated meat and bone meal from infected and rendered sheep (or infected cattle). In the early 1990s, human deaths in Britain were reportedly caused by a variant of CJD (vCJD) at incidences above the normal and rare natural occurrence, including several young people in which, it was suspected, that the disease was caused by consumption of BSE-infected beef. The variant form of CJD was characterized more by anxiety and depression than the dementia of classic CJD, and symptoms that lingered for years rather than weeks or months. The resulting arguments among societies, cultures, governments, countries, producers, consumers, scientists, and the media primarily in Europe led to various bans, boycotts, media-promulgated scares, animal slaughter, and public confusion that still linger today.

Nearly 50 years after Gajdusek began his investigations in New Guinea, we know considerably more about the prevalence of TSEs; we understand some of the commonalities of the occurrences of similar diseases such as kuru, BSE, chronic wasting disease, and CJD; and we understand some ele- ments of disease transmission and some characteristics of the possible agent. For example, Dr S. B. Prusiner (Nobel Prize in physiology in 1997) of the University of California at San Francisco has focused on the class of pathogens called prions, which cause neurodegenerative diseases. His lab has shown that prions can be created either spontaneously by mutation of a host protein or by exposure of the latter to prions from an exogenous source. (How exactly a protein would be infectious is still being investigated and explained.) Prions are primarily or entirely composed of a modified form of the prion protein and can multiply without a nucleic acid genome. Spongiform encephalopathies can be infectious or genetic, and in humans, sporadic CJD may occur in one in one million people. Interestingly, a recent article in Science (2003, 300:640-643) reported evidence that, worldwide, there has been genetic selection for a prion protein gene that has conferred relative resistance to these prion diseases during the evolution of modern humans.

We also understand that what we have learned has been the result of unlikely collaborations among scientists from highly diverse fields, that what is needed to understand this disease requires both extensive field work and highly controlled experiments, and that there is still much to be learned. But we have made progress. Earlier, in May 2003, the North American press reported a confirmed case of BSE in Canada. The overall rational response and effective containment of this outbreak illustrates the advances that have been made in the nearly 20 years since the BSE epidemic in Britain. In particular, the quality and depth of the information reported by the press has been encouraging. Although the headlines still employ the ludicrous label "mad cow disease," the content of the stories has been quite well based in current science. Two prominent examples have been columns in USA Today (May 21, 2003) and in The New York Times (May 25, 2003) that effectively reported not only on the Canadian BSE case but what has been learned from science about spongiform encephalopathies over the past 3 decades.

What a story about cannibalism and its ties to TSE, which are seemingly unrelated to range science, illustrates are a set of principles that can have direct application to today's issues engulfing rangeland management. These principles include 1) with difficult problems, we need people from many different disciplines involved (their backgrounds may be quite unrelated to each other or to specific problems); 2) solving difficult problems takes time, and solutions occur a bit at a time (we understand how TSEs are transmitted but are still not sure of the specifics of the transmitting agent); 3 ) relevant policies can be developed even from imperfect knowledge (such as don't feed infected meat to other animals or humans even if we don't yet know the specifics on infectious agents); 4) objectivity in the face of public perceptions and misperceptions is a formidable task (see the furor in Europe around "mad cow disease"); 5) complex topics can be effectively explained by an educated media; 6) honesty about both what we know and what we don't know is crucial (the 
proactive response to the Canadian infection was partly attributable to the credibility of the science); and 7) the best way to serve industry and producers is to provide both industry and the public with objective information and not to pander to or protect perceived interests as advocates.

As has been done in response to the threat of TSE, our rangeland resource problems of today will be best addressed by continued science, objective policies, diverse collaborations, energized education programs, well-articulated syntheses of our ecologically based principles, and continued development of credible management practices. This is the role of SRM.

\section{Complex Ecological Systems}

There has been considerable interest of late in rangeland monitoring and considerable debate about what needs to be done, who needs to do it, what needs to be measured, what it means, how quality of information can be ensured, who will have access to any data, and many other issues. Irrespective of how this debate may eventually play out, there will be an increased (renewed?) awareness that we are trying to capture a working understanding of complex ecological systems. Relevant to this discussion are the publications by James Brown (Professor in the Department of Biology at the University of New Mexico) and his colleagues on their longterm studies on the dynamics of rangeland environments in the Southwest. Several of these articles have been published in Science including Brown and Heske (1990, 250:1705) and Ernest and Brown (2001, 292:101). Recently, Dr Brown and 3 colleagues synthesized aspects of their work in Science (2001, 293:643-650). That article deserves further comment.

Since 1977, Brown and coworkers have studied sets of 0.5-acre plots near Portal, Arizona. They have selectively removed species of seed-eating rodents and ants from these plots and monitored various environmental responses over the past 25 years. They had hypothesized that some simple relations among precipitation, plant production, and rodent populations would be apparent. What they actually observed were some complex dynamics. Sometimes rodent populations increased during droughts and decreased during wet periods. When they removed rodents, such as kangaroo rats, from plots, they observed substantial increases in other seedeating rodents. However, increases were seen in both resident rodent species and species that migrated to the study site from surrounding areas.

There were also effects observed in response to the increased winter precipitation that this area has recorded during the last 2 decades of the 20th century. Some previously dominant species went extinct from these sites whereas other species increased. In addition, they observed spatial variation in these responses. In other words, different responses were seen in study areas just a few miles from their research site in Portal.

Removing a species, such as banner tail kangaroo rats, from these plots was a disturbance that cascaded through this system. For example, plant species changed on the abandoned rat mounds, certain fungi increased with increased seed availability, rattlesnakes and burrowing owls declined, harvester ants declined, and horned lizard declines followed. Yet, these systems didn't collapse as much as they restructured and compensated in response to these manipulated perturbations. In fact, with all of these changes, the total number of species remained relatively constant.

These studies illustrate that we live in a constantly changing environment, that small changes can result in significant responses, that changes are often unpredictable and complex, but that some responses can also be dampened and relatively insignificant. It is quite clear that these systems have thresholds in response to disturbances, and if a threshold is not exceeded, that effects of disturbances, such as species reductions or drought, are minimal. However, if thresholds are exceeded, the responses can be significant and long lasting.

An obvious broader implication of these studies is that it is very difficult to evaluate any system based on a one-time assessment or on a superficial monitoring of system properties such as species composition or biomass production. If we are truly going to understand these rangelands and our use of them, we need to record more seriously observations of important ecological attributes such as soil stability, hydrologic function, and biotic integrity. More importantly, we need to admit that we are often bringing simplistic, even naive, understandings to our decision-making processes concerning management of these rangelands. Our current approach, of management that is heavily influenced by court decree and public opinion, is both inadequate and inappropriate.

One appropriate and immediate action is for the scientific community to work more effectively to understand how these systems function and to identify reasonable ways to monitor their responses to changing environments and our management.

\section{Science}

Donald Kennedy is President Emeritus of Stanford University and the current Editor-in-Chief of Science, one of the world's most highly respected journals. He published a short article on sustainability, a topic certainly of interest to the readers of this section newsletter, in the Summer, 2005, issue of the Renewable Resources Journal (Sustainability, Can Science Get Us There? 23(2): 13-15). In his article, he wrestles with the complexity of the concept of sustainability in a dynamic world (ecologically, culturally, economically, politically, and socially). He writes that sustainability is an important concept, if we can agree on what it is. For this editorial, though, I do not want to wade into the topic of sustainability. I wish to discuss the issue of science more broadly. For this discussion, I want to focus on the last sentence of Kennedy's essay: "Science, it seems, is necessary; but it is not yet, alas, sufficient."

I agree, sort of. 
You might think that it is pretty cheeky of a government scientist of very modest credentials to discuss points made by one of the world's most respected science figures. Well, maybe, but the truth is he writes for a journal read around the world by millions, and I'm writing for, well, something less. It's not like I'm taking a big risk here.

Yet, for this audience I'd like to make what I think is an important point.

Science is necessary, and the questions we ask can certainly be more relevant and better tested, but the information we have is sufficient to a point. What is important to this discussion is a balanced perspective of what science can actually accomplish.

I think that natural resource issues, such as understanding effects of livestock grazing, are going to be, not science based, but science informed. There is a difference. Science based would mean that you have tested a specific question, and its hypothesis, for a particular situation and have data that support a strong inference regarding that hypothesis and question. Given the many different experimental settings, ecological sites, variable environments, array of local conditions, etc, that confound our scientific tests of these hypotheses, it is unlikely that we can develop data for strong inferences for more than a few specific situations. For those specific situations, we may be able to have management adapt to science-based information. That will be the exception.

Yet, for decades, we have worked to develop science-based principles that have broader application where management can be science informed. Those principles have been tested, and when in the hands of a capable land manager, they can be applied sufficiently. There are many examples of wellmanaged rangelands around New Mexico, the Southwest, the United States, and globally to attest to this fact. Science has played a role in that management, and often, it is not because specific experiments have been applied to every piece of well-managed rangeland. Science has informed some part of the management of those places. So, this is why I "sort of" agreed with Donald Kennedy's statement. Science has played a sufficient role in the past.

Now, though, the setting is different, and the "alas" part of his remark is quite appropriate. We now see rangelands as part of a large system, as part of larger landscapes, as having characteristics and dynamics different than what we had previously thought. We are now less concerned with their condition in relation to some point in the past and more concerned with their basic functioning and health. These newer perspectives are a result of science conducted around the world, and they point to the complexities of these rangelands.

An example here may be useful. If we look at data collected over many decades from the Las Cruces grazing district of the Bureau of Land Management (BLM) and if we looked at these data from the rangeland condition and trend perspective of old, we would tend to say that these BLM lands have been in a static trend since the 1930s. In other words, we really couldn't see noticeable improvement in the climax plant communities for many of these rangelands. However, if these same data are evaluated given a more thorough understanding of where the data are collected from across a landscape, the specific soil features, and the relationship of monitoring sites to the larger landscape, we start to see more useful and enlightening results. From work done by scientists and BLM personnel, we have learned that vegetation changes are being strongly influenced by landscape position and certain soil features. Subtle differences in particular soil attributes, such as a few decimeters difference in elevation, small percentage differences in maximum clay accumulation, and deep vs disseminated calcium carbonate distinguished soil patches that were vulnerable to vegetation loss from those that were resistant to them, may explain what is actually observed - that some sites are stable over time, some become more vegetated, and some become more bare. This is a very different conclusion than previously assumed. From this work, we will have to develop principles and apply those principles in an informed way to different landscapes.

So, is our science necessary and sufficient? It certainly is necessary in that it is addressing questions relevant to tens of millions of acres of rangeland and the people that use resources from these landscapes. It has been sufficient in that it has built principles in the past based on a coarse understanding of these systems. But more work needs to be done to make principles based on stronger inference.

Science is necessary; it has been coarsely sufficient for past management demands, but it is not yet, alas, sufficient for today's demands.

\section{Pink, Plastic High Heels}

The first and only time I saw her was as she came out from behind the counter to wash a petri dish. I'd guess she was in her early 20s, slender, with long black hair, and dressed in a gray pants suit of a style that would be quite characteristic of an urban office worker. It was supervisor-type attire and in stark contrast to her surroundings. She stood in the middle of this small dairy parlor, surrounded by 2 dozen dairy cows, a few farm workers, and about 6 or 7 sheep herders from Inner Mongolia relocated to this dairy cooperative on the outskirts of Xilinhot, a Chinese city of about 3 million people. She was performing a quick test on the fresh milk and using a hose in the center of the parlor periodically to clean the glassware.

Why she was there is quite a story. The term used by the Chinese central government is "ecological emigration." It refers to the movement of herders from their current and ancestral location on the steppe grasslands in Inner Mongolia to dairy cooperatives adjacent to the large cities in the region. These people are part of the 580 million of China's 1.3 billion who live on less than $\$ 2$ a day and who are now part of more than 100 million who have left the rural areas for work in cities. Estimates are that eventually 300-500 million will migrate in the next 10-20 years (The New York Times, September 12, 2004). In part, the move- 
ment is government-driven and a reaction to the overgrazed conditions of the steppe grasslands, which are a truly stunning expanse of perennial grasses such as Stipa and Agropyron. Intense dust storms originating from the region blow east each spring into Beijing and create havoc. Given that the herders each have a small allocation of land, there really is no way to provide relief to the landscapes short of complete rest for an extended period. The Chinese government has invested in the development of extensively managed irrigated farms adjacent to the cities that produce the forage and silage for these new dairy cooperatives (and potatoes under contract to the fast food industry that has expanded into Asia). Given the new growth in the Chinese economy, the urban Chinese population (hundreds of millions) is increasing its income and consumption of various products, including dairy (and french fries). Relocated herders, each with a few Holsteins, now provide a set of agricultural products in great demand. The herders don't have to move to these dairy villages, but they do have to leave their former homes, and alternatives to the dairy villages are few. So they now live in suburban conditions where the government provides the infrastructures, such as milking parlors placed within the villages, to harvest and market their products. They are paid for the milk per kg produced and pay for the forage and silage used. It is still a subsistence existence, but one viewed by the government as a solution to abject poverty and resource deterioration.

Standing in one of these milking parlors in a dairy village in central Inner Mongolia, I watched some relocated herders disdain the modern milking machinery and hand-milk their few dairy cows. I'm not sure if their disdain was for modern technology, or its links to the government, or both. As the milk from each cow was individually collected, they lugged or carted the liquid output to the classic feed barn scale at one end of the parlor and the gray-suited woman behind the counter.

Her shoes, though, made her the protagonist of this story. She was wearing pink, plastic, pointed-toed high heels. The points were at least 3 inches long. The kind of point you would expect if they had been dipped in a vat of hot pink sauce and slowly extracted leaving a cooled ribbon of perceived fashion extending beyond the toes. She had made a stark statement by her attire that she was in a position of authority and a bold statement with her heels that she was neither poor nor rural. In among this environment of people forced to move from their homes of abject poverty and of ancient agricultural traditions, clashed against modern technologies, I was just struck by these shoes and that she could make this kind of statement in a milking parlor within the rangelands of Inner Mongolia. Even in a region where livestock and livestock products are a highly important part of both the culture and the food supply, the faces of agriculture and of a society of well more than a billion people are changing. Things may be changing elsewhere in the world, but I don't see change this rapid where I live. In part, the pace of change is rapid in China because the resources are severely stressed.

There are lessons here, but I have to first get over that image of pink high heels.

Author is Supervisory Scientist, US Department of Agriculture, Agricultural Research Service, Jornada Experimental Range, MSC 3JER, NMSU. PO Box 30003, Las Cruces, NM 88003, khavstad@nmsu.edu. 